\title{
3D Mandibular Positioning After Rapid Maxillary Expansion in Class II Malocclusion
}

\author{
Carolina BARATIERI \\ Matheus ALVES JR \\ Eduardo Franzotti SANT'ANNA \\ Matilde da Cunha Gonçalves NOJIMA \\ Lincoln Issamu NOJIMA
}

Department of Orthodontics, Dental School, UFRJ - Federal University of Rio de Janeiro, RJ, Brazil

\begin{abstract}
This study investigated, using cone beam computed tomography (CBCT), the spatial mandibular positioning after rapid maxillary expansion (RME) in Class II Division 1 malocclusion. This prospective study evaluated 17 children (mean initial age 10.36 years old) presenting Class II, Division 1 malocclusion and skeletal maxillary constriction that underwent to RME Haas' protocol. CBCT was performed before treatment (T1), immediately after the stabilization of expander screw (T2) and after the retention period of 6 months (T3). The scans were managed in Dolphin Imaging ${ }^{\circledR} 11.0$ software, where landmarks (right and left condylion, right and left gonion, and menton) were positioned and measured in relation to sagittal, coronal and axial plane to verify, respectively, transverse, anteroposterior and vertical displacement of the mandible. Paired Student's t-test was used to identify significant differences $(p<0.05)$ between T1 and T2, T2 and T3, and T1 and T3. After RME, right and left gonion moved downward (1.11 mm and $0.89 \mathrm{~mm})$ and menton displaced downward $(1.90 \mathrm{~mm})$ and backward $(1.50 \mathrm{~mm})$. During the retention period, only anteroposterior displacement was significant, with the right and left gonion $(0.97 \mathrm{~mm}$ and $1.26 \mathrm{~mm})$ and the menton $(2.29 \mathrm{~mm})$ moving forward. Three-dimensional assessment of the mandible in Class II Division 1 patients subjected to RME showed a transitory backward and downward mandibular positioning, without any lateral displacement. The 6-month retention period allowed the mandible shifting significantly forward, exhibiting a more anterior position compared with the initial condition, even remaining in a more downward direction.
\end{abstract}

Key Words: Palatal expansion technique, malocclusion angle Class II, cone beam computed tomography.

\section{INTRODUCTION}

The most common diagnostic finding in Class II Division 1 malocclusion is mandibular skeletal retrusion (1). This find turns the spatial positioning of the mandible in relation to the face an important, if not, the most important relevant aspect in Class II malocclusion treatment. Several studies $(2,3)$ have shown that, in addition to the sagittal and vertical problems related to this malocclusion, it is frequently associated to transverse discrepancies. The significant reduction in maxillary width found in subjects with Class II Division 1 malocclusion compared to normal occlusion individuals, is considered a possible cause of mandibular retrusion, which makes the correction of the transverse discrepancy frequently necessary (4).

Class II malocclusion characteristics in all 3 spatial planes (sagittal, frontal and axial) are already present in the primary dentition and remain in the mixed dentition with no self-correction (5). According to Haas (6), as soon as the transverse maxillary deficiency is diagnosed, correction is recommended, regardless of other skeletal discrepancies since transverse growth ends earlier than the others dimensions.

Rapid maxillary expansion (RME) has been successfully used to correct skeletal transverse discrepancy in growing patients. However, after the mid-palatal suture opening, not only transversal, but also vertical and anteroposterior changes occur $(6,7)$. The clockwise rotation of the mandibular plane, resulting from the inferior-posterior position of the mandible after RME, has been one of the most reported effects (6). This finding raises questions about RME in Class II patients since this mandibular position would be undesirable and could worsen the sagittal problem already existing.

With the increasing assessment to computed 
tomography $(\mathrm{CT})$ in dentistry $(8,9)$, 3-dimensional (3D) images turned the measurements of craniofacial structures more precise, as there are no projections or overlapping of bilateral structures, allowing visualization in sagittal, coronal and axial planes. Cone beam computed tomography (CBCT) allows complete scanning of the face within few seconds, providing more accurate information with less ionizing irradiation (10).

In view of the great need frequency for maxillary transverse discrepancy correction in Class II Division 1 malocclusion, the aim of the present study was to evaluate the spatial mandibular positioning in sagittal, coronal and axial planes, using CBCT images.

\section{MATERIAL AND METHODS}

This prospective clinical study was performed at the Department of Orthodontics of the Federal University of Rio de Janeiro in Brazil after granting approval by the local Ethics Committee (Protocol. 128/20090052.0.239.000-09) and written informed consent from patients' parents. Seventeen children ( 8 boys and 9 girls, mean ages of 10.67 and 10.05 years old, respectively), presenting Class II Division 1 malocclusion and skeletal maxillary narrowing, were selected.

Inclusion criteria were: chronological age ranging from 7 to 12 years; Class II Division 1 malocclusion with at least $2 \mathrm{~mm}$ toward a Class II molar relationship (at least 1 side); Class II skeletal relationship $\left(\mathrm{ANB}>4^{\circ}\right.$ ) (11); maxillary skeletal transverse deficiency (distance from J point to facial frontal line $>12 \mathrm{~mm}$ ) (12); and to be before pubertal growth spurt. Skeletal maturation was assessed in the cervical vertebrae on the lateral cephalometric image obtained from CT scans (13).

Even not being an exclusion criterion, none of the patients had visible posterior crossbite. The transverse problem was first evaluated clinically and diagnosed as maxillary narrowing, when the patient projected the mandible until a Class I relationship, and the posterior relationship was edge to edge or in crossbite.

All patients were subjected to RME therapy with a soft tissue-borne appliance, standardized with stainless steel wire of 0.047 inch in diameter (Rocky Mountain Orthodontics, Denver, CO, USA) and expansion screw of $11 \mathrm{~mm}$ (Magnum 600.303.30, Dentaurum, Ispringen, Germany). The Haas activation protocol for children under 14 years old was used (14). The expander was activated one complete turn $(0.8 \mathrm{~mm})$ at the time it was placed. Thereafter, it was activate daily by a quarter turn in the morning and a quarter turn in the evening during 2-3 weeks until the palatal surface of the maxillary molar contacted buccal surface of the mandibular molar, when the patient projected the mandible and reached Class I relationship. Then, the screw was fixed with 0.012-inch double thread ligature and kept in place passively until completing 6 months, when the expander was removed.

CBTC scans were taken before treatment (T1), immediately after stabilization of expansion screw (T2), and after 6 months of retention (T3). The first scan was taken at least 2 months before the begging of the clinical procedures in order to extend the period between the $\mathrm{X}$-ray exposures. All scans were taken in the same cone beam machine (i-CAT; Imaging Sciences International, Hatfield, PA, USA), according to a standard protocol (120 KVp, $5 \mathrm{~mA}$, FOV $16 \times 22 \mathrm{~cm}$, voxel $0.4 \mathrm{~mm}$, and 20 s of scan time). During scanning, all patients were in maximum intercuspation.

The scans data at T1, T2, and T3 were exported in DICOM (digital imaging and communication in medicine) format and imported into Dolphin $3 \mathrm{D}^{\circledR}$ software (version 11.0; Dolphin Imaging, Chatsworth, CA, USA) for further analysis.

Once imported, using specific software tools, each 3D-volumetric data set was standardized using the following reference planes $(15,16)$ (Fig. 1): axial plane (axi), passing through right and left infraorbital points (ROr and LOr) as well as right porium; coronal plane (cor), passing through left and right porium (RPo and LPo), perpendicular to axi; and sagittal plane (sag), passing through nasion point $(\mathrm{N})$, perpendicular to axi and cor planes. This procedure was necessary in order to replicate the $3 \mathrm{D}$-volumetric data set positions in all experimental times (T1, T2 and T3) as well as to evaluate skeletal changes regarding such stable planes.

After standardization, it was possible to view both volume and multiplanar reconstructions (MPR) in

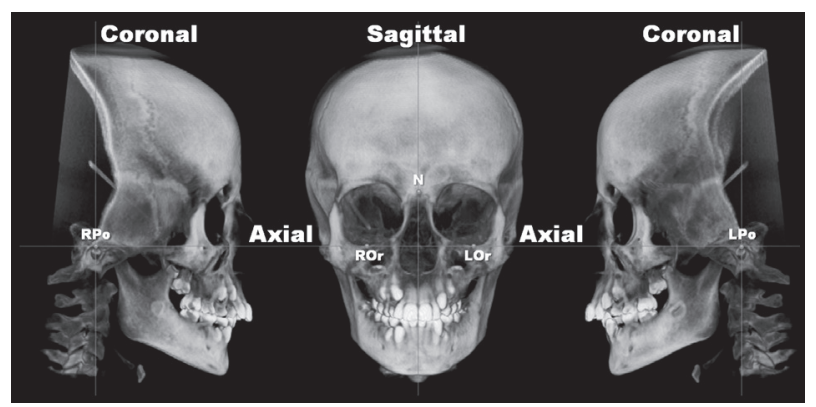

Figure 1.3D-reconstruction of the head after orientation by references planes (Dolphin Imaging ${ }^{\circledR}$ software/Orientation function). 
sagittal, coronal and axial slices (Fig. 2). Mandibular anatomic points (Table 1) were evidenced with 0.025 $\mathrm{mm}$ diameter landmarks in the MPR views and in the volume. The scrolling of the planes and the $3 \mathrm{D}$ image view allowed localizing the landmarks and, once the landmark was fixed on the sagittal slice, it was possible to visualize it on the others slices (Figs. 2-4). Thereafter the linear distance of each landmark ( $\mathrm{rCo}, \mathrm{CC}$, rGo, $1 \mathrm{Go}$ and $\mathrm{Me}$ ) was taken in relation to coronal, axial and sagittal planes to verify mandibular anteroposterior, vertical and transverse changes, respectively (Fig. 5). Reference plane positions were recorded to allow the initial position to be resumed whenever necessary.

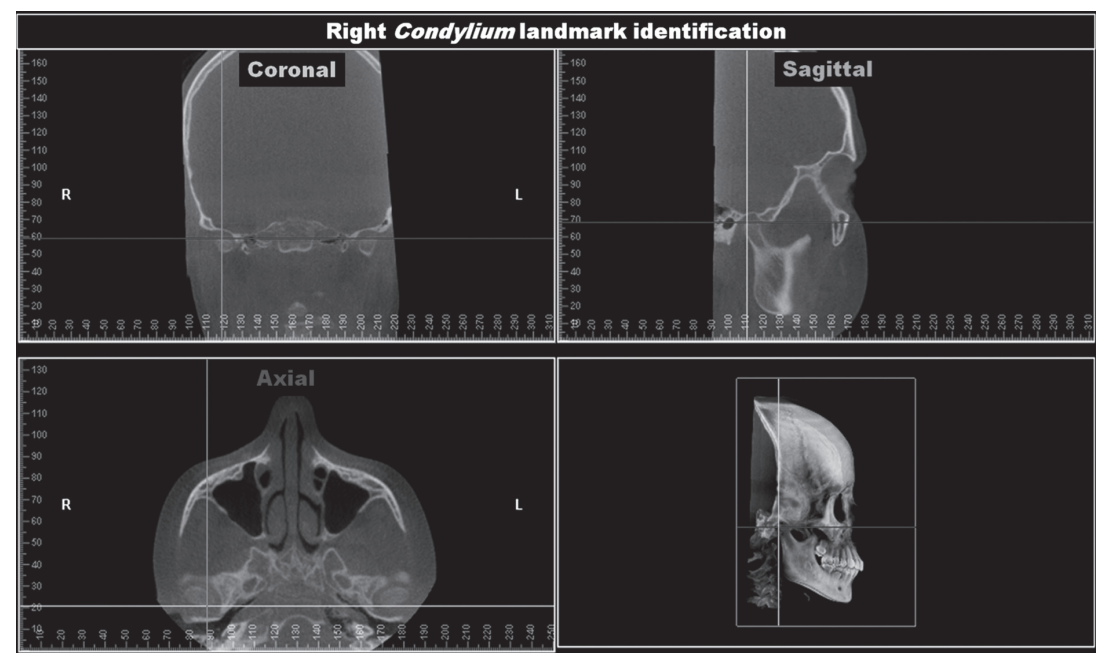

Figure 2. Right condylion landmark identification on multiplanar reconstruction views and 3D-reconstruction (Dolphin Imaging ${ }^{\circledR}$ software).

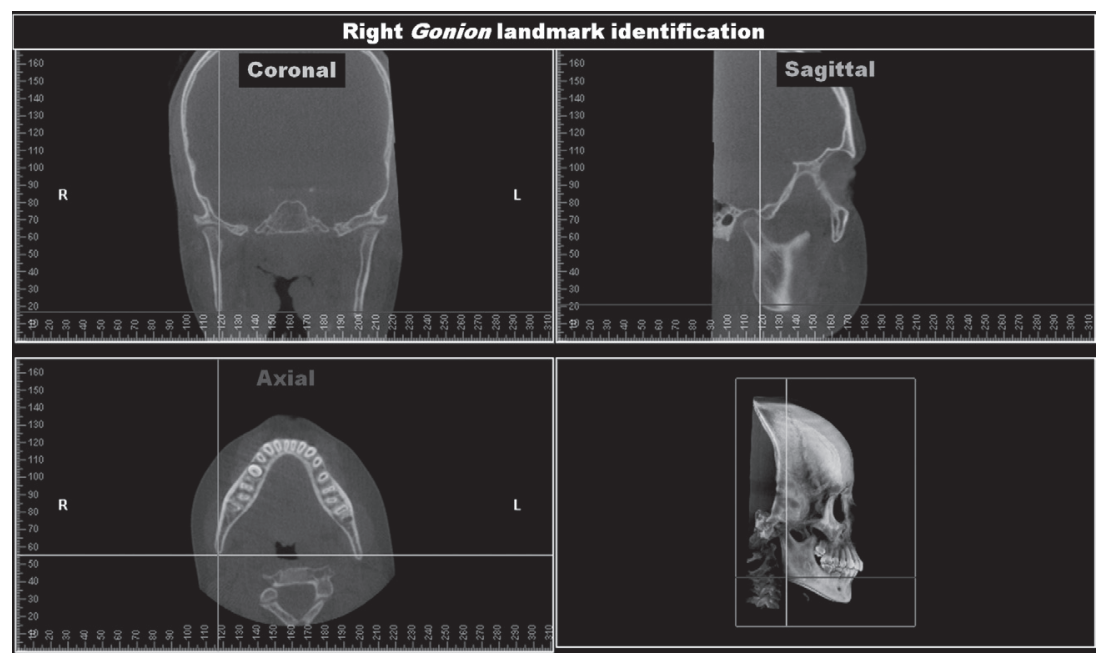

Figure 3. Right gonion landmark identification on multiplanar reconstruction views and 3D-reconstruction (Dolphin Imaging ${ }^{\circledR}$ software).
In order to avoid possible measurement errors, two similar computers, software and monitors [23.0-inch flat panel color (Samsung SyncMaster 2370; Samsung Electronics America Inc., Ridgefield Park, NJ, USA) with a resolution of $1920 \times 1080$ at $60 \mathrm{~Hz}$ and a 0.2655 $\mathrm{mm}$ dot pitch, operated at $32 \mathrm{bit}$ ] were used side by side, in darkened proper room. This enabled simultaneous manipulation of CBCT images during the location of the planes and landmarks in the 3 experimental times for each patient, with $\mathrm{T} 1$ as reference. The measurements at $\mathrm{T} 1, \mathrm{~T} 2$, and $\mathrm{T} 3$ were performed separately by the same examiner at 1 -week intervals.

Prior to the measurements, 15 scans were randomly selected and all the measurements, after 3D-recostruction orientation and landmarks identification, were realized at 2 different times, under the same, within a 2-week interval. Intraclass correlation test was applied to verify the intra-rater concordance $(95 \%$ confidence interval) for all variables (rCo-cor, rCo-axi, rCo-sag, 1Co-cor, 1Co-axi, 1Co-sag, rGo-cor, rGo-axi, rGo-sag, 1Go-cor, 1Go-axi, 1Go-sag, Me-cor, Me-axi and Me-sag). Concordance index was greater than 0.95 for all variables analyzed, except for the variables with $\mathrm{Co}$, which were 0.85 .

\section{Statistical Analysis}

Means, standard deviations, minimum and maximum values were calculated for each variable at $\mathrm{T} 1, \mathrm{~T} 2$, and $\mathrm{T} 3$ as well as the changes observed between $\mathrm{T} 1$ and $\mathrm{T} 2$, $\mathrm{T} 2$ and $\mathrm{T} 3$, and $\mathrm{T} 1$ and $\mathrm{T} 3$. After finding the normal data distribution by means of Kolmogorov-Smirnov non-parametric test, the paired Student's t test was used to identify statistically significant differences $(\mathrm{p}<0.05-95 \%$ confidence interval) between T2 and T1, T3 and T2, and $\mathrm{T} 3$ and $\mathrm{T} 1$. Statistical analysis was carried out using the SPSS software version 16.0 (SPSS Inc., Chicago, IL, USA). 


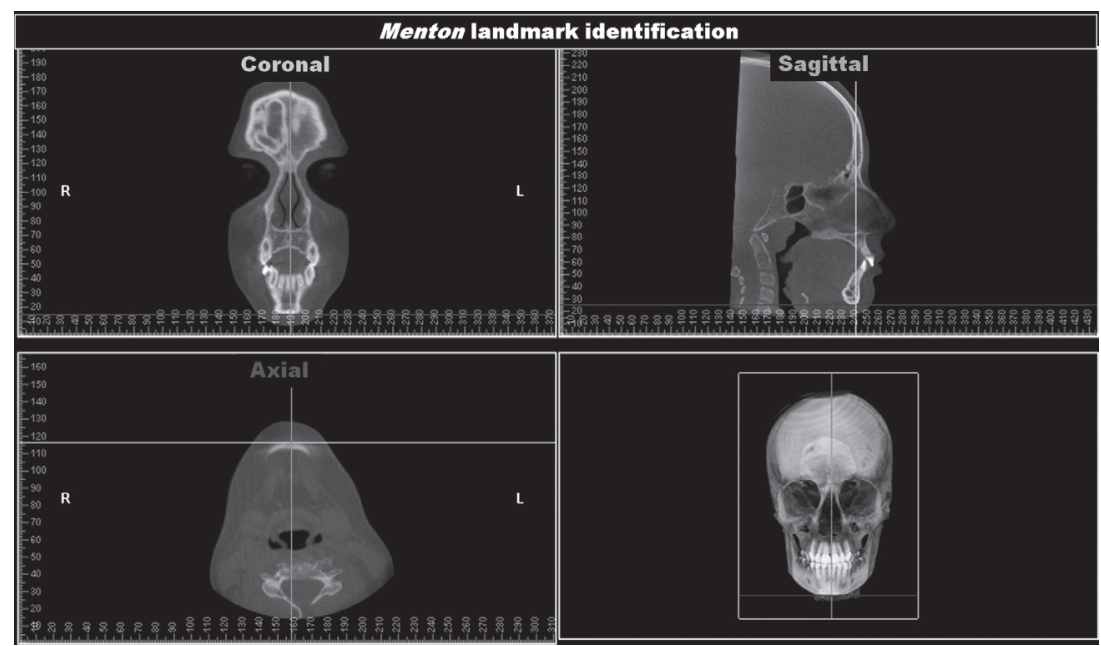

Figure 4. Menton landmark identification on multiplanar reconstruction views and 3D-reconstruction (Dolphin Imaging ${ }^{\circledR}$ software).

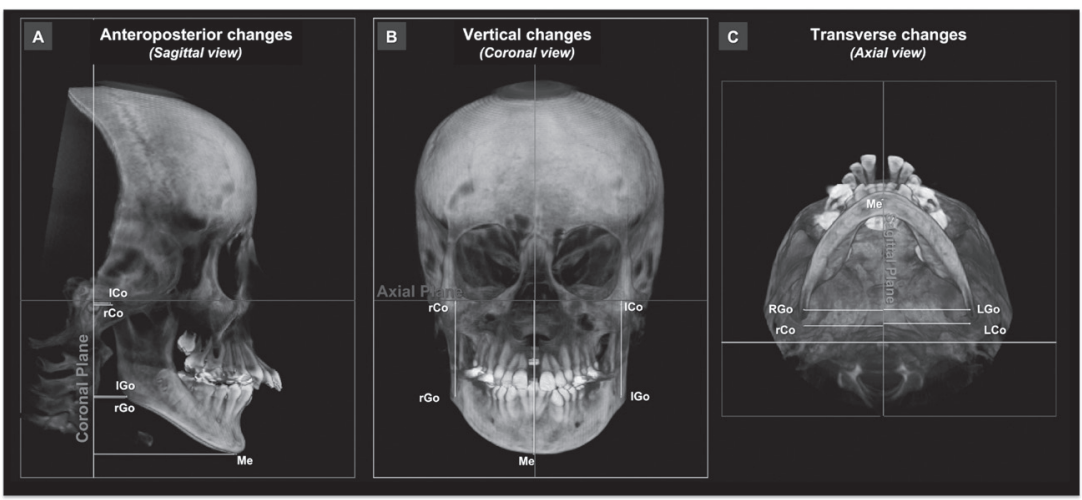

Figure 5. Orthogonal measurements. $\mathrm{A}=$ landmarks $(\mathrm{Co}$, $\mathrm{Go}$ and $\mathrm{Me})$ in relation to the coronal plane (anteroposterior changes); $\mathrm{B}=$ landmarks in relation to the axial plane (vertical changes) and $\mathrm{C}=$ landmarks in relation to the sagittal plane (transverse changes).

\section{RESULTS}

The mid-palatal suture separation was clinically confirmed in all patients with the inter-incisor diastema opening after 3-5 days following expander activation and then confirmed on the CBCT image realized at $\mathrm{T} 2$.

During the retention period, one of the patients returned without the expander, which had been replaced by a removable retention appliance, but data at $\mathrm{T} 3$ were not computed though.

The results regarding descriptive analysis and paired Student's t-test are presented in Tables 2 and 3, respectively.

\section{DISCUSSION}

The aim of this prospective clinical study was to evaluate the vertical, anteroposterior and transverse mandibular changes after the correction of transverse discrepancy in Class II malocclusion patients. 3D assessment of RME outcomes required the choice of stable reference for same registration in each period evaluated. In terms of facial changes, references

Table 1. Landmarks definition in the CBCT images.

\begin{tabular}{|c|c|c|c|c|}
\hline $\begin{array}{l}\text { Landmarks } \\
\text { (abbreviations) }\end{array}$ & $\begin{array}{l}\text { Anatomic } \\
\text { region }(3 \mathrm{D})\end{array}$ & Sagittal view & Coronal view & Axial view \\
\hline $\begin{array}{l}\text { Right condylion } \\
(\mathrm{rCo})\end{array}$ & Right condyle & $\begin{array}{l}\text { Posterior-superior- } \\
\text { most point }\end{array}$ & $\begin{array}{l}\text { Superior-middle- } \\
\text { most point }\end{array}$ & $\begin{array}{l}\text { Middle point in the axial slice determined } \\
\text { previous by the sagittal and coronal view }\end{array}$ \\
\hline $\begin{array}{l}\text { Left condylion } \\
(\mathrm{lCo})\end{array}$ & Left condyle & $\begin{array}{l}\text { Posterior-superior- } \\
\text { most point }\end{array}$ & $\begin{array}{l}\text { Superior-middle- } \\
\text { most point }\end{array}$ & $\begin{array}{l}\text { Middle point in the axial slice determined } \\
\text { previous by the sagittal and coronal view }\end{array}$ \\
\hline $\begin{array}{l}\text { Right gonion } \\
\text { (rGo) }\end{array}$ & $\begin{array}{l}\text { Right mandibular } \\
\text { body angle }\end{array}$ & $\begin{array}{l}\text { Posterior-inferior- } \\
\text { most point }\end{array}$ & Middle point & Posterior-most point \\
\hline $\begin{array}{l}\text { Left gonion } \\
\text { (1Go) }\end{array}$ & $\begin{array}{l}\text { Left mandibular } \\
\text { body angle }\end{array}$ & $\begin{array}{l}\text { Posterior-inferior- } \\
\text { most point }\end{array}$ & Middle point & Posterior-most point \\
\hline Menton (Me) & $\begin{array}{l}\text { Chin lower } \\
\text { border }\end{array}$ & $\begin{array}{l}\text { Inferior-anterior- } \\
\text { most point }\end{array}$ & Inferior-most point & Middle-inferior-most point \\
\hline
\end{tabular}


utilized should not rely on structures that might have changed between the CBCT acquisitions. For this reason, we used planes already known in conventional cephalometrics, which allowed the standardization of the 3D-reconstruction and the evaluation of mandible displacement in the axial, sagittal and coronal view.

Immediately after RME (T1-T2), the greatest effect was in vertical direction showed by a significant $(p<0.01)$ distance increase of the left and right gonion $(1.11 \mathrm{~mm}$ and $0.89 \mathrm{~mm}$, respectively) and menton $(1.90 \mathrm{~mm})$ from the axial plane. This vertical difference between the anterior and posterior region revealed a mandible clockwise rotation, confirmed by a significant backward of the menton $(1.50 \mathrm{~mm}, \mathrm{p}<0.05)$. The right and left condylion had no changes in all three dimensions. Such displacement may have been the result of either premature contact involving over-expanded palatine cusps and the inferior maxillary displacement caused by the opening of mid-palatal suture (17).

During the retention period(T2-T3), no significant vertical alteration was observed. All landmarks tended to reduce their distance in relation to axial plane, however, without resuming to initial vertical position at the end (T1-T3). Differently, in relation to the coronal plane, left and right Gonion moved forward $0.97 \mathrm{~mm}(\mathrm{p}<0.05)$ and $1.26 \mathrm{~mm}(\mathrm{p}<0.001)$, respectively and Menton had the major forward displacement, $2.29 \mathrm{~mm}(\mathrm{p}<0.01)$.

The initial changes found had indeed worsened the skeletal pattern of the Class II malocclusion. However, during the retention period (T2-T3), the correction of the transverse deficiency allowed the mandible to move forward significantly. As reported in an earlier study (18), the mandible shifted forward to a more comfortable occlusal position, thus reducing the posterior crossbite tendency caused by RME.

Differently from the RME active phase, lasting only 2-3 weeks, the retention period was longer (6 months) and vertical growth of the maxilla might have had some influence on such mandibular backward displacement. It is expected in untreated subjects from 9 years old a vertical growth of $1.5 \mathrm{~mm}$ per year for boys and $1.2 \mathrm{~mm}$ for girls (19). The fact is that the vertical component, resulting either from RME or growth, limits the horizontal mandibular component, thus preventing forward positioning of the menton (20). Controlling the maxillary shift to avoid downward movement of the maxilla would probably allow greater anterior expression of the mandible $(6,20)$ but needs further investigation.

Table 2. Descriptive analysis of measurements ( $\mathrm{mm}$ ) obtained in pre-treatment (T1), immediately after expansion (T2) and after 6 months of retention (T3) for each landmark in relation to sagittal, coronal and axial plane.

\begin{tabular}{|c|c|c|c|c|c|c|c|c|c|c|c|c|c|c|}
\hline \multirow{2}{*}{ Landmarks } & \multirow{2}{*}{ Time } & \multirow{2}{*}{$\mathrm{n}$} & \multicolumn{4}{|c|}{ Sagittal plane } & \multicolumn{4}{|c|}{ Coronal plane } & \multicolumn{4}{|c|}{ Axial plane } \\
\hline & & & Mean & Min & Max. & S.D & Mean & Min. & Max. & S.D & Mean & Min. & Max. & S.D \\
\hline \multirow{3}{*}{$\begin{array}{l}\text { Right } \\
\text { condylion }\end{array}$} & $\mathrm{T} 1$ & 17 & 43.28 & 38.64 & 48.72 & 2.88 & 8.98 & 2.66 & 13.65 & 2.30 & 3.03 & 0 & 6.70 & 1.86 \\
\hline & $\mathrm{T} 2$ & 17 & 43.39 & 39.43 & 50.77 & 3.14 & 9.29 & 1.76 & 13.66 & 2.58 & 3.29 & 0 & 7.80 & 1.95 \\
\hline & $\mathrm{T} 3$ & 16 & 43.13 & 39.34 & 46.49 & 2.23 & 8.94 & 2.62 & 10.61 & 1.83 & 2.70 & 0 & 6.77 & 1.82 \\
\hline \multirow{3}{*}{$\begin{array}{l}\text { Left } \\
\text { condylion }\end{array}$} & $\mathrm{T} 1$ & 17 & 43.20 & 36.81 & 47.71 & 2.69 & 9.13 & 2.13 & 14.25 & 2.58 & 3.02 & 0 & 5.63 & 1.98 \\
\hline & $\mathrm{T} 2$ & 17 & 42.84 & 36.87 & 48.62 & 2.91 & 9.25 & 1.62 & 14.32 & 2.75 & 3.26 & 0 & 7.61 & 2.10 \\
\hline & $\mathrm{T} 3$ & 16 & 42.95 & 36.78 & 49.32 & 3.26 & 8.77 & 2.01 & 12.09 & 2.18 & 3.14 & 0 & 6.38 & 1.88 \\
\hline \multirow{3}{*}{$\begin{array}{l}\text { Right } \\
\text { gonion }\end{array}$} & $\mathrm{T} 1$ & 17 & 40.31 & 36.45 & 45.37 & 2.91 & 18.57 & 11.41 & 26.73 & 3.74 & 49.65 & 43.87 & 57.45 & 4.33 \\
\hline & $\mathrm{T} 2$ & 17 & 40.10 & 35.50 & 46.39 & 2.93 & 18.03 & 9.40 & 26.39 & 4.00 & 50.76 & 43.88 & 59.05 & 4.52 \\
\hline & T3 & 16 & 40.12 & 35.91 & 44.10 & 2.46 & 18.75 & 10.67 & 26.40 & 3.95 & 50.12 & 44.65 & 57.92 & 4.13 \\
\hline \multirow{3}{*}{$\begin{array}{l}\text { Left } \\
\text { gonion }\end{array}$} & $\mathrm{T} 1$ & 17 & 39.57 & 33.88 & 44.61 & 3.31 & 18.29 & 12.76 & 28.48 & 3.65 & 49.83 & 42.66 & 58.08 & 4.17 \\
\hline & $\mathrm{T} 2$ & 17 & 39.84 & 34.37 & 45.61 & 3.49 & 17.65 & 10.87 & 26.61 & 3.61 & 50.72 & 42.49 & 59.71 & 4.78 \\
\hline & $\mathrm{T} 3$ & 16 & 39.64 & 33.44 & 45.37 & 3.74 & 18.67 & 11.55 & 27.12 & 3.54 & 50.64 & 44.43 & 59.07 & 4.34 \\
\hline \multirow{3}{*}{ Menton } & $\mathrm{T} 1$ & 17 & 0.58 & -2.25 & 4.24 & 1.48 & 72.71 & 58.91 & 88.33 & 7.58 & 77.85 & 68.05 & 87.22 & 5.33 \\
\hline & $\mathrm{T} 2$ & 17 & 0.39 & -2.60 & 5.67 & 1.88 & 71.21 & 55.82 & 84.39 & 7.75 & 79.75 & 69.04 & 87.77 & 5.18 \\
\hline & T3 & 16 & -0.33 & -4.18 & 2.19 & 1.81 & 72.67 & 57.73 & 88.00 & 7.12 & 78.98 & 69.01 & 88.67 & 5.38 \\
\hline
\end{tabular}

$\mathrm{n}=$ sample number; $\operatorname{Min}=$ minimum; Max = maximum; $\mathrm{SD}=$ standard deviation. 
The evaluation of the long-term effects of RME revealed no significant anteroposterior and vertical skeletal alterations (21). The small number of studies evaluating Class II patient subjected to RME as a single intervention must have been one of the causes for the different results found in the present study. Based on earlier studies (22) and clinical reports (23), we do believe that different types of malocclusions have different responses to RME, mainly mandibular, thus emphasizing the importance of evaluating the results of each kind of malocclusion.

With regard to transverse effects, landmarks were measured in relation to the coronal plane. Minimal and no significant $(\mathrm{p}>0.05)$ changes were found, either immediately after RME or during the retention period. Some mandibular lateral displacement is often related after maxillary expansion (24), differing from the findings in our study. This could be attributed that none of the patients in our study had visible posterior unilateral crossbite.
This study contributes to reduce the concern about RME in Class II patients. The so important mandible positioning will not worsen the anteroposterior skeletal problem already existing though vertical control should not be despised. Long-term randomized controlled trials are needed to strengthen the evidence, but ethical reasons turns difficult to follow up Class II malocclusion patients without intervening when maxillary transverse discrepancy is diagnosed.

In conclusion, the mandibular 3D assessment in Class II Division 1 malocclusion immediately after RME showed a transient backward and downward positioning of the mandible, without any lateral displacement. The 6-month retention period with Haas expander allowed the mandible shifting significantly forward, exhibiting a more anterior position compared with the initial condition, even remaining in a more downward direction. The number of children included in this study, although sufficient to detect statistically significant changes is small to generalized the results, thus it should be

Table 3. Results regarding transverse (sagittal plane), anteroposterior (coronal plane) and vertical (axial plane) changes between pretreatment and post-expansion (T2 - T1), retention and post-expansion (T3 - T2), and retention and initial (T3 - T1).

\begin{tabular}{|c|c|c|c|c|c|c|c|c|c|c|}
\hline \multirow{2}{*}{ Landmarks } & \multirow{2}{*}{ Time } & \multicolumn{3}{|c|}{ Sagittal plane } & \multicolumn{3}{|c|}{ Coronal plane } & \multicolumn{3}{|c|}{ Axial plane } \\
\hline & & Mean & $\mathrm{SD}$ & $\mathrm{p}$ value & Mean & $\mathrm{SD}$ & $\mathrm{p}$ value & Mean & SD & $\mathrm{p}$ value \\
\hline \multirow{3}{*}{$\begin{array}{l}\text { Right } \\
\text { condylion }\end{array}$} & $\mathrm{T} 1-\mathrm{T} 2$ & 0.11 & 1.08 & 0.69 & 0.31 & 1.33 & 0.35 & 0.26 & 1.43 & 0.45 \\
\hline & $\mathrm{T} 2-\mathrm{T} 3$ & -0.21 & 0.86 & 0.35 & -0.08 & 1.16 & 0.78 & -0.49 & 0.84 & 0.07 \\
\hline & $\mathrm{T} 1-\mathrm{T} 3$ & -0.19 & 1.05 & 0.47 & 0.25 & 1.11 & 0.34 & -0.19 & 1.04 & 0.48 \\
\hline \multirow{3}{*}{$\begin{array}{l}\text { Left } \\
\text { condylion }\end{array}$} & $\mathrm{T} 1-\mathrm{T} 2$ & -0.36 & 1.41 & 0.31 & 0.12 & 1.47 & 0.73 & 0.25 & 1.01 & 0.33 \\
\hline & $\mathrm{T} 2-\mathrm{T} 3$ & 0.20 & 1.61 & 0.63 & -0.17 & 1.12 & 0.54 & -0.12 & 1.08 & 0.67 \\
\hline & $\mathrm{T} 1-\mathrm{T} 3$ & -0.18 & 1.17 & 0.54 & -0.04 & 1.35 & 0.89 & 0.07 & 0.89 & 0.74 \\
\hline \multirow{3}{*}{ Right gonion } & $\mathrm{T} 1-\mathrm{T} 2$ & -0.21 & 0.96 & 0.38 & -0.54 & 1.74 & 0.22 & 1.11 & 1.28 & $0.003 * *$ \\
\hline & $\mathrm{T} 2-\mathrm{T} 3$ & 0.42 & 1.19 & 0.18 & 0.97 & 1.55 & $0.03 *$ & -0.12 & 1.04 & 0.65 \\
\hline & $\mathrm{T} 1-\mathrm{T} 3$ & -0.13 & 1.32 & 0.69 & 0.38 & 1.26 & 0.24 & 0.93 & 1.09 & $0.004 * *$ \\
\hline \multirow{3}{*}{ Left gonion } & $\mathrm{T} 1-\mathrm{T} 2$ & 0.27 & 1.02 & 0.29 & -0.64 & 1.37 & 0.06 & 0.89 & 1.30 & $0.01 *$ \\
\hline & $\mathrm{T} 2-\mathrm{T} 3$ & -0.17 & 1.11 & 0.55 & 1.26 & 0.93 & $0.000 * * *$ & -0.47 & 1.19 & 0.13 \\
\hline & $\mathrm{T} 1-\mathrm{T} 3$ & 0.18 & 1.02 & 0.48 & 0.54 & 1.53 & 0.18 & 1.23 & 1.28 & $0.002 * *$ \\
\hline \multirow{3}{*}{ Menton } & $\mathrm{T} 1-\mathrm{T} 2$ & -0.19 & 1.77 & 0.66 & -1.50 & 2.28 & $0.01 *$ & 1.90 & 1.19 & $0.000 * * *$ \\
\hline & $\mathrm{T} 2-\mathrm{T} 3$ & -0.29 & 1.43 & 0.29 & 2.29 & 2.14 & $0.001 * *$ & -0.37 & 1.06 & 0.18 \\
\hline & $\mathrm{T} 1-\mathrm{T} 3$ & 0.5 & 1.20 & 0.09 & 0.74 & 1.29 & $0.03 *$ & 1.54 & 1.11 & $0.000 * * *$ \\
\hline
\end{tabular}

$\mathrm{n}=$ sample number; $\mathrm{SD}=$ standard deviation; Level of significance $=* \mathrm{p}<0.05 ; * * \mathrm{p}<0.01 ; * * * \mathrm{p}<0.001$. Mean value positive $(+)=$ forward (sagittal plane), outward (coronal plane), downward (axial plane) displacement. Mean value negative $(-)=$ backward (sagittal plane), inward (coronal plane), upward (axial plane) displacement. 
considered a pilot study for 3D evaluation of RME in Class II malocclusion patients.

\section{RESUMO}

O objetivo do presente estudo foi avaliar, por meio de tomografia computadorizada de feixe cônico (TCFC), o posicionamento espacial da mandíbula após expansão rápida da maxila (ERM) na maloclusão de Classe II. Este estudo prospectivo avaliou 17 crianças (idade média inicial de 10,36 anos) com maloclusão de Classe II Divisão 1 e atresia esquelética da maxila, as quais foram submetidas ao protocolo de Haas para ERM. TCFCs foram realizadas antes do tratamento (T1), imediatamente após estabilização do parafuso expansor (T2) e após o período de 6 meses de contenção (T3). Com o software Dolphin Imaging ${ }^{\circledR}, 11.0$, foi possível a manipulação das imagens e as mensurações das landmarks (condílio direito e esquerdo; gônio direito e esquerdo; e mento) em relação aos planos sagital, coronal e axial, para que fosse possível verificar os efeitos transversais, anteroposteriores e verticais, respectivamente. O teste $\mathrm{t}$ de Student pareado foi utilizado para identificar significância estatística $(p<0,05)$ entre os intervalos T2 e T1, T3 e T2, e T3 e T1. Imediatamente após a ERM o gônio direito e esquerdo deslocaram para baixo $1,11 \mathrm{~mm}$ e $0,89 \mathrm{~mm}$, respectivamente; e o mento deslocou 1,90 mm para baixo e $1,50 \mathrm{~mm}$ para trás. Durante o período de contenção houve apenas deslocamento significativo no sentido anteroposterior; sendo que o gônio direito, esquerdo e o mento deslocaram para frente, $0,97 \mathrm{~mm}, 1,26 \mathrm{~mm}$ e 2,29 $\mathrm{mm}$, respectivamente. A avaliação tridimensional de pacientes com maloclusão de Classe II Divisão 1 mostrou que a mandíbula se posiciona transitoriamente para trás e para baixo logo após a ERM. Os 6 meses seguintes de contenção permitiram que a mandíbula se deslocasse significativamente para frente, exibindo uma posição mais anterior, mesmo permanecendo mais inferior.

\section{ACKNOWLEDGEMENTS}

The authors acknowledge financial support from CAPES andFAPERJ.

\section{REFERENCES}

1. McNamara J. Components of Class II malocclusion in children 8-10 years of age. Angle Orthod 1981;51:177-202.

2. Tollaro I, Baccetti T, Franchi L, Tanasescu CD. Role of posterior transverse interarch discrepancy in Class II, Division 1 malocclusion during the mixed dentition phase. Am J Orthod Dentofacial Orthop 1996;110:417-422.

3. Alarashi M, Franchi L, Marinelli A, Defraia E. Morphometric analysis of the transverse dentoskeletal features of Class II malocclusion in the mixed dentition. Angle Orthod 2003;73:21-25.

4. Lima AC, Lima AL, Filho RMAL, Oyen OJ. Spontaneous mandibular arch response after rapid palatal expansion: a longterm study on Class I malocclusion. Am J Orthod Dentofacial Orthop 2004;126:576-582.

5. Baccetti T, Franchi L, McNamara Jr JA, Tollaro I. Early dentofacial features of Class II malocclusion: a longitudinal study from the deciduous through the mixed dentition. Am J Orthod Dentofacial Orthop 1997;111:502-509.

6. Haas AJ. Rapid expansion of the maxillary dental arch and nasal cavity by opening the midpalatal suture. Angle Orthod 1961;31:73-90.
7. Lima Filho RMA, Ruellas ACO. Long-term anteroposterior and vertical maxillary changes in skeletal Class II patients treated with slow and rapid maxillary expansion. Angle Orthod 2007;77:870874.

8. Oliveira CAP, Meurer MI, Pascoalato C, Silva SRC. Cone-beam computed tomography analysis of the apical third of curved roots after mechanical preparation with different automated systems. Braz Dent J 2009;20:376-381.

9. Baratieri C, Canongia ACP, Bolognese AM. Relationship between maxillary canine intra-alveolar position and maxillary incisor angulation: a cone beam computed tomography study. Braz Dent J 2011;22:146-150.

10. Silva MAG, Wolf U, Heinicke F, Bumann A, Visser H, Hirsh E. Cone-beam computed tomography for routine orthodontic treatment planning: a radiation dose evaluation. Am J Orthod Dentofacial Orthop 2008;133.

11. Riedel RA. The relation of maxillary structures to cranium in malocclusion and in normal occlusion. Angle Orthod 1952;22:142145.

12. Ricketts RM. Perspectives in the clinical application of cephalometrics. Angle Orthod 1981;51:115-150.

13. Shi H, Scarfe WC, Farman AG. Three-dimensional reconstruction of individual cervical vertebrae from cone-beam computedtomography images. Am J Orthod Dentofacial Orthop 2007;131:426-432.

14. Haas AJ. Palatal expansion:just the beginning of dentofacial orthopedics. Am J Orthod Dentofacial Orthop 1970;57:219-255.

15. Baratieri C, Nojima LI, Alves Jr M, Souza MMGd, Nojima MG. Transverse effects of rapid maxillary expansion in Class II malocclusion patients: a cone-beam computed tomography study. Dental Press J Orthod 2011;15:89-97.

16. Alves Jr M, Baratieri C, Nojima LI. Assessment of mini-implant displacement using cone beam computed tomography. Clin Oral Impl Res 2011 [Epub ahead of print. DOI: 10.1111/j.16000501.2010.02092.x.].

17. Wertz R. Skeletal and dental changes accompanying rapid midpalatal suture opening. Am J Orthod Dentofacial Orthop 1970;58:41-65.

18. Wendling LK, McNamara JA, Franchi L, Baccetti T. A prospective study of the short-term treatment effects of the acrylic-splint rapid maxillary expander combined with the lower Schwarz appliance. Angle Orthod 2005;75:7-14.

19. Riolo ML, Moyers RE, McNamara JA, Hunter W. An atlas of craniofacial growth - cephalometric standards from the University School Growth Study. Michigan: University of MichiganMonograph Craniofacial Series, 1974.

20. Schudy FF. Vertical growth versus anteroposterior growth as related to function and treatment. Angle Orthod 1964;34:75-93.

21. Garib DG, Henriques JFC, Carvalho PEG, Gomes SC. Longitudinal effects of rapid maxillary expansion. Angle Orthod 2007;77:442-448.

22. McNamara JA, Sigler LM, Franchi L, Guest SS, Baccetti T. Changes in occlusal relationships in mixed dentition patients treated with rapid maxillary expansion. Angle Orthod 2010;80:230-238.

23. Lima Filho RMA, Lima AC, de Oliveira Ruellas AC. Spontaneous correction of Class II malocclusion after rapid palatal expansion. Angle Orthod 2003;73:745-752.

24. Kiki A, Nihat K, Oktay HS. Condylar asymmetry in bilateral posterior crossbite patients. Angle Orthod 2007;77:77-81.

Received April 13, 2011 Accepted August 9, 2011 